\title{
21. Informing Tax Policy Legislation: Thinking differently about consultation processes
}

\author{
Mary Craig
}

The phrase 'tax policy' does not usually elicit wild excitement in the general public. So, for fear of disengaging readers of this volume with a long presentation on a dry topic, my contribution will briefly use the field of tax policy to explore the new dimensions of community consultation. Together with Gail Kelly (Chapter 22), I will particularly explore the use of online forums for engaging citizens on tax policy. I am not, however, going to pretend that this is a transformational use of a piece of technology. I note that Martin Stewart-Weeks (Chapter 9) covers many of these aspects in his earlier chapter. Nonetheless, new technology has greatly assisted Inland Revenue in New Zealand to engage more people in the formation of tax policy than could have been achieved with traditional methods. The success of these new approaches to citizen engagement has encouraged our organisation specifically to investigate other new technologies which could our improve citizen engagement methods and, more broadly, to look at things differently and take risks.

This contribution will provide some background to the new citizen engagement approaches adopted by New Zealand's Inland Revenue organisation before Kelly elaborates on the experiences and effects of these changes.

We all know that citizens have a legal obligation to comply with tax legislation, as with other legislation. At Inland Revenue we have tried hard to make it easy for people to comply with tax legislation, whether it is via the service delivery interface, or to comply with the new or established policies that we administer. In New Zealand there is now an extensive formal legislative consultation process in place and it is prescribed and very detailed. Any new legislation or any significant change to legislation must be put out to the general public for consultation and comment. This has been done in the past through traditional means and we would generally have about 10 such consultations each year.

The responses that we get from these consultations helps us frame the legislation, as well as flagging any associated issues that may be of interest, whether they are innocuous or contentious, or whether they merely highlight emerging trends or problems in which the government of the day may be interested. 
There is no doubt though, that these traditional consultations are long, complicated processes and sometimes expensive in time and resources. The consultation documents that we publish range between 30 to 60 pages in length, sometimes longer, and usually what we get back, in kind, are similar length documents. They are almost invariably detailed text-based documents. We will accept submissions or comments by post or by email, and sometimes they are written by hand. This is the standard consultation process for tax legislation that has prevailed for some time. It connects principally with the 'usual suspects', with whom we regularly consult and, in most cases, we can anticipate their views.

Having said that, there are still a whole range of other activities and functions that our organisation undertakes that are not strictly about tax policy. While tax policy constitutes around 50 per cent of Inland Revenue's work, we also have service delivery obligations, whether they concern student loans, or working out tax credits for families. In addition, we administer KiwiSaver - New Zealand's state-run retirement fund scheme - and child support payments.

But, to return to the theme of this presentation, the problems with the standard consultation process have become evident and Inland Revenue has begun to seek to go beyond the traditional limited approach. Feedback on tax policy changes tended to be generalised or 'chunked up' and submitted by a third party. In Inland Revenue, we wanted to begin to engage those people who do not typically provide feedback about changes in tax legislation. Such citizens tend to hold individual views, rather than those representing a particular association or interest group or demographic. Consequently, what we were looking for in terms of feedback and consultation were individual inputs and responses.

An obvious response to the problem of improving the breadth of consultation was to start thinking about information technology and the fact that Inland Revenue had yet to exploit its potential, other than to receive documents via email. It was clear that that new information technologies presented an exciting variety of ways in which we could consult with people and 'push their buttons' - including through an emphasis on new forms of social media and other forms of technology. The consultation process no longer needed to be confined to text and lengthy documentation. Contemporary information technology could provide a diversity of consultative methods.

Another important advantage in harnessing this new technology is the time that is saved as a consequence. Traditionally, consultations about tax legislation have been lengthy processes; they can take months, sometimes years. But, in utilising online forums, consultation was occurring in real time, or as near to real time as we could possibly get. Consequently, we have now moved to a platform where submitters are talking to each other, commenting on each 
other's views, as well as talking to us in Inland Revenue, and talking to the government more generally. In this way it is a real conversation. And, although some of this input must be filtered out, we are also getting rich and valuable information - quickly. Thanks to new technology, we are now able to send our information out more quickly and in a manner which is more manageable for both individuals and groups. 